\title{
Influence of cutting speed and tool wear on the surface integrity of the titanium alloy Ti-1023 during milling
}

\author{
Yang Houchuan • Chen Zhitong • Zhou ZiTong
}

Received: 18 January 2014 / Accepted: 18 May 2014 / Published online: 28 December 2014

(C) The Author(s) 2014. This article is published with open access at Springerlink.com

\begin{abstract}
This study focuses on the machined surface integrity of the titanium alloy Ti-10V-2Fe-3Al (Ti-1023) during face milling. Surface roughness, machining defect, microhardness, and microstructure variations are investigated at different cutting speeds and tool average flank wear $(V B)$ values. Experimental results show that surface roughness increases when cutting speed is increased from 40 to $100 \mathrm{~m} \mathrm{~min}^{-1}$ and decreases when cutting speed is increased from 100 to $300 \mathrm{~m} \mathrm{~min}^{-1}$ by using a new tool. Moreover, surface roughness values are stable when cutting speed is increased by using a worn tool at $\mathrm{VB}=0.2 \mathrm{~mm}$ and increases when $\mathrm{VB}$ is increased. As for defects, the machining defect is determined to be dependent on cutting speed and tool wear directions. Microhardness is decreased to $35 \mu \mathrm{m}$ beneath the machined surface at different cutting speeds by using a new tool. The influence of tool wear on hardening is significant, with the depth of hardening being less than $55 \mu \mathrm{m}$ by using a worn tool at $\mathrm{VB}=0.2 \mathrm{~mm}$ and reaching $130 \mu \mathrm{m}$ at $\mathrm{VB}=0.35 \mathrm{~mm}$. No significant phase transformation or evident deformation can be observed at different cutting speeds by using a new tool (initial wear). Severe plastic deformation and deep alteration of the microstructure in the machined surface are produced with VB from initial wear to $\mathrm{VB}=0.35 \mathrm{~mm}$. VB is best maintained at less than $0.2 \mathrm{~mm}$ for finish machining of Ti1023.
\end{abstract}

Keywords Surface roughness $\cdot$ Microhardness $\cdot$ Machining defect $\cdot$ Microstructure $\cdot$ Titanium alloy Ti-1023

Y. Houchuan $\cdot$ C. Zhitong $\cdot$ Z. ZiTong

School of Mechanical Engineering and Automation, Beihang

University, Beijing 100191, China

Y. Houchuan $(\bowtie)$

Department of Aviation Repair Engineering, The First Aeronautical Institute of Air Force, Xinyang, Henan Province 464000, China e-mail: xyyanghc@126.com

\section{Introduction}

The titanium alloy Ti-10V-2Fe-3Al (Ti-1023) has been extensively used to manufacture critical components, such as aircraft fuselage, wing, landing gear, and helicopter rotor parts, employed in the aviation and aerospace industries because of its high strength-to-weight ratio, excellent corrosion and fatigue resistance, high fracture toughness, good casting properties, and hardenability [1]. These critical components are frequently used in extreme environments. The processing quality of these components directly affects the performance of the entire aircraft structure [2]. Finishing is still needed to satisfy tolerance requirements or achieve improved surface integrity. However, similar to other titanium alloys, Ti-1023 cannot be easily machined because of its high strength, chemical reactivity, and low thermal conductivity. Numerous investigations have confirmed that the performance, longevity, and reliability of machined components during their service life are considerably dependent on their surface quality [3]. Surface integrity requirements (e.g., surface roughness, machining defect, microhardness, microstructure, and residual stress) must be satisfied to eliminate severe failures produced by fatigue, creep, and stress corrosion cracking generated on the surface of components [4-6]. Hence, the quality of a machined surface is important to satisfy the increasing demands for sophisticated component performance.

Many studies have been conducted to investigate the surface integrity of titanium alloys, including Ti-6Al-4V, Ti6242S, and Ti-6246 [7-13]. Sun and Guo [8] reported that roughness is obviously influenced by cutting speed and tool wear. As cutting speed increases, roughness value decreases. Consequently, the machined surface tends to become smooth toward the end of tool life at a cutting speed of $60 \mathrm{~m} \mathrm{~min}^{-1}$. Other researchers have reported that cutting speed [7, 9-11, $15]$ is effective to a certain degree in increasing surface roughness. As cutting speed is increased, surface roughness 
increases for Ti-6246 and Ti-64 [7, 8, 13, 14]. Moreover, tool parameters, such as tool insert shape, tool average flank wear $(V B)$, and the selected coolant, affect surface roughness values [16]. Tool wear close to tool half-life results in a slight decrease in surface roughness values than that in the previous period. When half-life is reached, the tool fits the workpiece and surface roughness is decreased. After half-life, however, the tool starts to wear severely and causes anomalies in the tool-workpiece contact surface, which increases surface roughness significantly [13]. Many forms of surface defects have been reported in literature $[12,15,17-20]$. The main forms include surface drag, material pullout/cracking, feed marks, adhered material particles, tearing surface, chip layer formation, microchip debris, surface plucking, deformed grains, surface cavities, slip zones, laps (materials folded onto the surface), and lay patterns [12, 15, 17-20]. Cutting speed can affect the amount of microchip debris on the surface [12, 17]. The most commonly reported surface damages are plastic deformation of the grains in the direction of cutting and surface cavities. Jeelani and Ramakrishnan [21, 22] reported that surface cavities are formed by chip fragmentation on the workpiece surface or by welding between the titanium adhering to the tool and the workpiece. The adhering layers can then be deposited as smeared layers on the workpiece in other locations.

Sun and Guo [8] reported that the hardness of the disturbed layer of the machined surface increases significantly when flank wear is high. When cutting speed is high, microhardness diminishes on the surface. Che-Haron and Jawaid [7] found that, on the surface of turned Ti- 64 at $\mathrm{Vc}=100 \mathrm{~m} \mathrm{~min}^{-1}, \mathrm{fz}=$ $0.25 \mathrm{~mm}$ tooth $^{-1}$ to $0.35 \mathrm{~mm}$ tooth $^{-1}$, and $\mathrm{DOC}=2 \mathrm{~mm}$, microhardness values are higher $(\sim 420 \mathrm{HV})$ than those at the bulk material level $(\sim 340 \mathrm{HV})$ because of the work-hardening effect on the surface and the softening of the sublayer of the material. These researchers noted that flank wear affects microstructure. They also discovered that microhardness increases with the increase in cutting speed. Ginting and Nouari
[12] showed that microhardness in the subsurface can be divided into three regions during dry machining of the titanium alloy Ti-6242S: the soft subsurface, the hard subsurface, and the hard bulk material regions. The soft subsurface region is formed by thermal softening during the aging process, whereas the hard subsurface region results from the cyclic internal work-hardening process.

Hughes et al. [23] showed that the grains close to the surface undergo deformation and lengthening by following the cutting direction when turning Ti-6Al-4V with lubrication. The depth of microstructural alterations beneath the surface has been observed to increase when cutting speed increases. Moreover, prolonged machining with a worn tool has been found to increase microstructural alterations in the material in the form of severe plastic deformation and thick "disturbed" layer on the machined surface [13, 24]. As a tool wears, plastic deformation on the workpiece increases during machining of titanium alloys Ti-64 and Ti-6246, which contributes to the formation of white layers [7, 13].

Although knowledge on the surface integrity of titanium alloys produced during machining is critical to their performance, investigations on the titanium alloy Ti-1023 have not been conducted. This study aims to investigate the surface integrity of the titanium alloy Ti-1023 in finish machining. Surface roughness, defect, microhardness, and microstructure during face milling of Ti-1023 are used to determine the possible effects of cutting speed and tool wear on the surface integrity of the machined surface.

\section{Experimental}

\subsection{Workpiece materials}

Ti-1023 is a near- $\beta$ titanium alloy type (Fig. 1). The $\beta$-phase proportion typically varies from 40 to $50 \%$. The $\beta$ phase in pure titanium has a body-centered cubic structure and remains
Fig. 1 Phase composition analysis

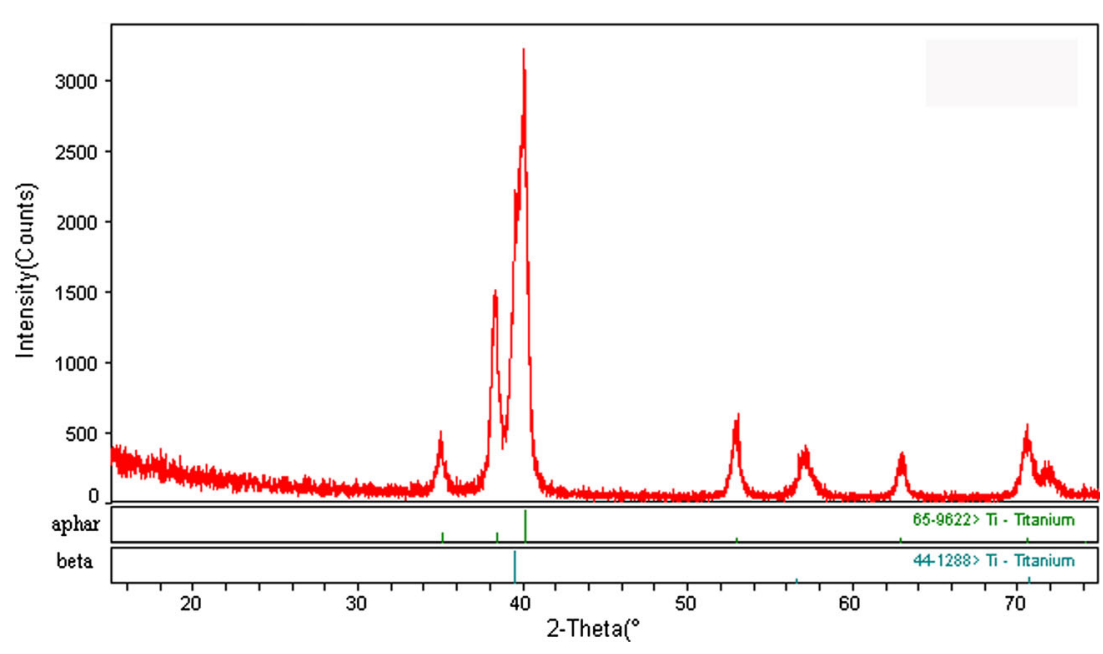


Table 1 Nominal composition of Ti-1023 [wt.\%]

\begin{tabular}{lllllllll}
\hline $\mathrm{Ti}$ & $\mathrm{Al}$ & $\mathrm{V}$ & $\mathrm{Fe}$ & $\mathrm{C}$ & $\mathrm{N}$ & $\mathrm{H}$ & $\mathrm{Y}$ & $\mathrm{O}$ \\
\hline Bal. & $2.6 \sim 3.4$ & $9.0 \sim 11$ & $1.6 \sim 2.2$ & $<0.05$ & $<0.05$ & $<0.015$ & $<0.005$ & $<0.13$ \\
\hline
\end{tabular}

steady from room temperature to its melting point. The $\alpha$ phase can be translated into the $\beta$ phase by reducing temperature and adding alloying elements to titanium. After continuous aging treatment, the $\alpha$ phase connects the block to the fine short rod sheet and is uniformly distributed in the matrix $\beta$ phase. Consequently, the structure has high strength. The excellent combination of strength, ductility, and toughness can be obtained in near- $\beta$ Ti-1023 alloy by a large deformation in near- $\beta$ forging [25]. The nominal composition and physical properties of Ti-1023 are listed in Tables 1 and 2, respectively [26]. The workpiece plates, with a dimension of $20 \mathrm{~mm} \times$ $20 \mathrm{~mm} \times 30 \mathrm{~mm}$, have been prepared by face milling.

\subsection{Machining}

Milling experiments are conducted on a three-axis computer numerical control milling machine, with a maximum spindle rotation speed of $8,000 \mathrm{rpm}$ under wet conditions with a water-soluble cutting fluid ( $8 \%$ concentration). The singlelayer physical vapor deposition-coated TiAlN carbide (Sandvik R390-1704 31E-PMS30T), with a corner radius $(R)$ of 3 to $3.2 \mathrm{~mm}$, is used in all experiments. Cutting speed, flank wear, and other cutting conditions are listed in Table 3. A series of experiments is conducted with one cutter tooth in down milling. The machined surfaces are first milled in the cutting edge, but are not reprocessed in the cutting edge.

\subsection{Measuring surface integrity}

Surface roughness $(\mathrm{Ra})$ is measured by using the Form Talysurf Intra surface profiler (Taylor Hobson Ltd., IL, USA). The 3D surface topography images are observed by using a confocal optical microscope equipped with Mirox AM white light interferometer. The observed surface area is $857 \mu \mathrm{m} \times 638 \mu \mathrm{m}$. The tearing surface is observed by using a JSM 6010 scanning electron microscope (JEOL Ltd., Tokyo, Japan).

The microhardness of the metallographic specimens is measured by using the FM-800 microhardness tester with a load of $100 \mathrm{gf}(0.98 \mathrm{~N})$ and a waiting time of $10 \mathrm{~s}$. On the

Table 2 Physical properties of Ti-1023 at room temperature

\begin{tabular}{llllll}
\hline $\begin{array}{l}\text { Tensile } \\
\text { strength } \\
(\mathrm{Mpa})\end{array}$ & $\begin{array}{l}\text { Yield } \\
\text { strength } \\
(\mathrm{Mpa})\end{array}$ & $\begin{array}{l}\text { Elastic } \\
\text { modulus } \\
(\mathrm{GPa})\end{array}$ & $\begin{array}{l}\text { Elongation } \\
(\%)\end{array}$ & $\begin{array}{l}\text { Hardness } \\
(\mathrm{HV})\end{array}$ & $\begin{array}{l}\text { Fracture } \\
\text { toughness } \\
(\mathrm{MPa} \cdot \sqrt{m})\end{array}$ \\
\hline 1,005 & 1,105 & 106 & $4 \sim 10$ & $\sim 375$ & $\geq 60$ \\
\hline
\end{tabular}

machined surface at an end-face distance of $5 \mathrm{~mm}$, the $3^{\circ}$ angle chamfered face is cut via walking thread cutting. Then, the chamfered face is ground and polished, as shown in Fig. 2. If the indentation for microhardness measurement is penetrated at every $57 \mu \mathrm{m}$ of the chamfered face until the hardness of the bulk material is attained ( $\sim 375 \mathrm{HV})$, then every $3-\mu \mathrm{m}$ depth beneath the machined surface can be calculated. Microhardness measurements are repeated thrice for each inspection point to obtain average values.

Samples are chemically etched in a bath that comprises $4 \%$ $\mathrm{HNO}_{3}, 2 \% \mathrm{HF}$, and $94 \% \mathrm{H}_{2} \mathrm{O}$ to examine the modification of the microstructure within the machined surface. The specimens are etched for approximately $15 \mathrm{~s}$ to obtain the clear microstructure of Ti-1023. The microstructure is observed by using a digital microscope (VHX-1000) to analyze the quality of the machined surfaces at a magnification of $\times 500$.

\section{Results and discussions}

The results and discussions are focused on the workpiece surface integrity aspects in finish machining of Ti-1023.

\subsection{Surface topography}

\subsubsection{Surface roughness}

Many parameters are used in literature and in the industry to evaluate surface roughness. Among 2D surface roughness parameters, the most popular is average roughness, which is expressed as Ra, as shown in Eq. (1). Mathematically, Ra is the arithmetic value of the departure of the profile from the centerline along the sampling length $[27,28]$ and can be expressed as follows:

$\mathrm{Ra}=\frac{1}{l} \int_{x=0}^{l}|Z(x)| \mathrm{d} x$.

Table 3 Cutting conditions for the experimental work

\begin{tabular}{ll} 
Tool average flank wear $(\mathrm{VB})(\mathrm{mm})$ & $0,0.1,0.2,0.35$ \\
Cutting speed $V \mathrm{c}\left(\mathrm{m} \mathrm{min}^{-1}\right)$ & $20,40,60,80,100,200,300$ \\
Depth of cut $(\mathrm{mm})$ & 1 \\
Feed rate $(\mathrm{mm}$ tooth & $-1)$ \\
\hline
\end{tabular}




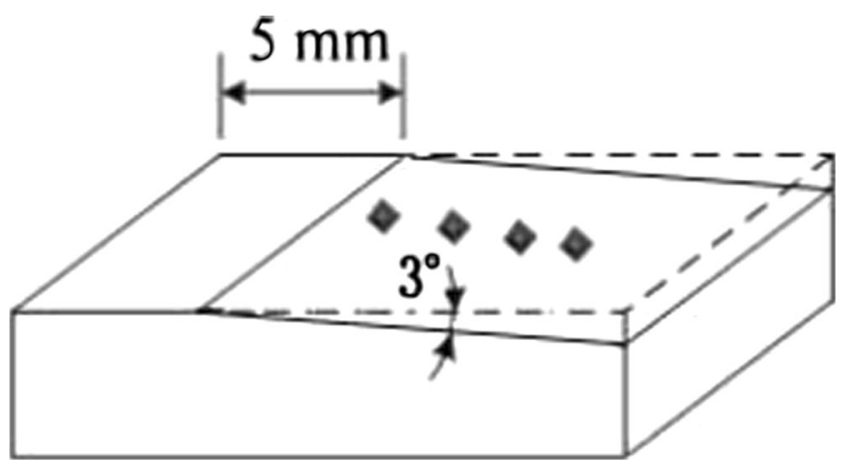

Fig. 2 Microhardness test specimen

$\mathrm{Ra}$ is affected by many factors [7, 8, 29]. The effects of cutting speed and VB on surface roughness are investigated in this study. Average Ra data recorded from each cutting condition during the experiments are shown in Fig. 3. In this figure, surface roughness in the feed direction and perpendicular to the feed direction decreases initially, increases within the range of 40-100 $\mathrm{m} \mathrm{min}^{-1}$, and then decreases at greater than $100 \mathrm{~m} \mathrm{~min}^{-1}$, with increasing cutting speed when a new tool is used. The valleys of surface roughness in both directions are observed at cutting speeds of 40 and $300 \mathrm{~m} \mathrm{~min}^{-1}$. However, the peak of surface roughness is observed at the cutting speed of $100 \mathrm{~m} \mathrm{~min}^{-1}$. Surface roughness values in both directions range from 0.2 to $0.6 \mu \mathrm{m}$. Cutting temperature is low at the cutting speed of less than $40 \mathrm{~m} \mathrm{~min}^{-1}$. Consequently, surface micromelting is thin, plastic deformation is small, and tool contour is copied on the machined surface. Thus, the texture of the machined surface is regular and smooth, and surface roughness decreases accordingly. Within the range of 40-100 $\mathrm{m} \mathrm{min}^{-1}$, as cutting speed increases, the effect of cutting forces on the intermittent cutting process increases, the degree of strain hardening of the materials becomes severe, and resistance to deformation in the shear zone increases. Consequently, cutting vibration increases with increasing cutting speed. Moreover, machined surface defects

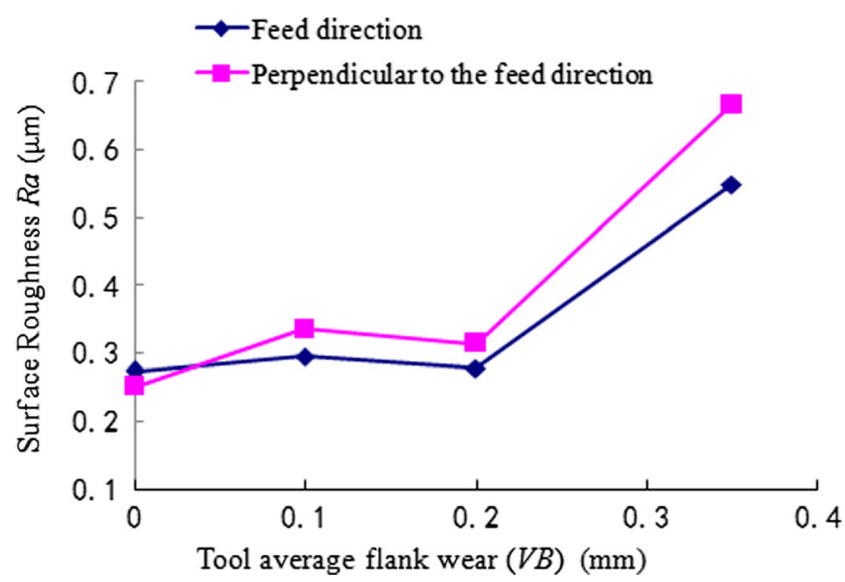

Fig. 4 Influence of VB on surface roughness $\left(V \mathrm{c}=40 \mathrm{~m} \mathrm{~min}^{-1}, \mathrm{fz}=\right.$ $0.08 \mathrm{~mm}_{\text {tooth }}^{-1}$, ap $=1 \mathrm{~mm}$, ae $=20 \mathrm{~mm}$ )

increase, surface morphology deteriorates, and surface roughness increases. When cutting speed is greater than $300 \mathrm{~m} \mathrm{~min}^{-1}$, the total cutting heat created in the cutting zone increases during machining. Most of the cutting heat is diverted by the chipping and cutting fluids. Given the poor thermal conductivity of Ti-1023, the temperature of the machined surface is evidently increased (Fig. 9), whereas chip deformation and hardness on the machined surface decrease $[30,40]$, cutting forces are probably reduced, the cutting process is smooth, and surface roughness decreases.

As shown in Fig. 3, surface roughness values in the feed direction are slightly lower than those perpendicular to the feed direction obtained by using a worn tool at $\mathrm{VB}=0.2 \mathrm{~mm}$. Surface roughness values in both directions are less than $0.45 \mu \mathrm{m}$. This result can be attributed to the grooves of the cutting edge and flank topography mapping generated on the worked surface. Roughness values are stable at cutting speeds ranging from 40 to $300 \mathrm{~m} \mathrm{~min}^{-1}$. This result can be attributed to deformation on the flank face or the adherence of the

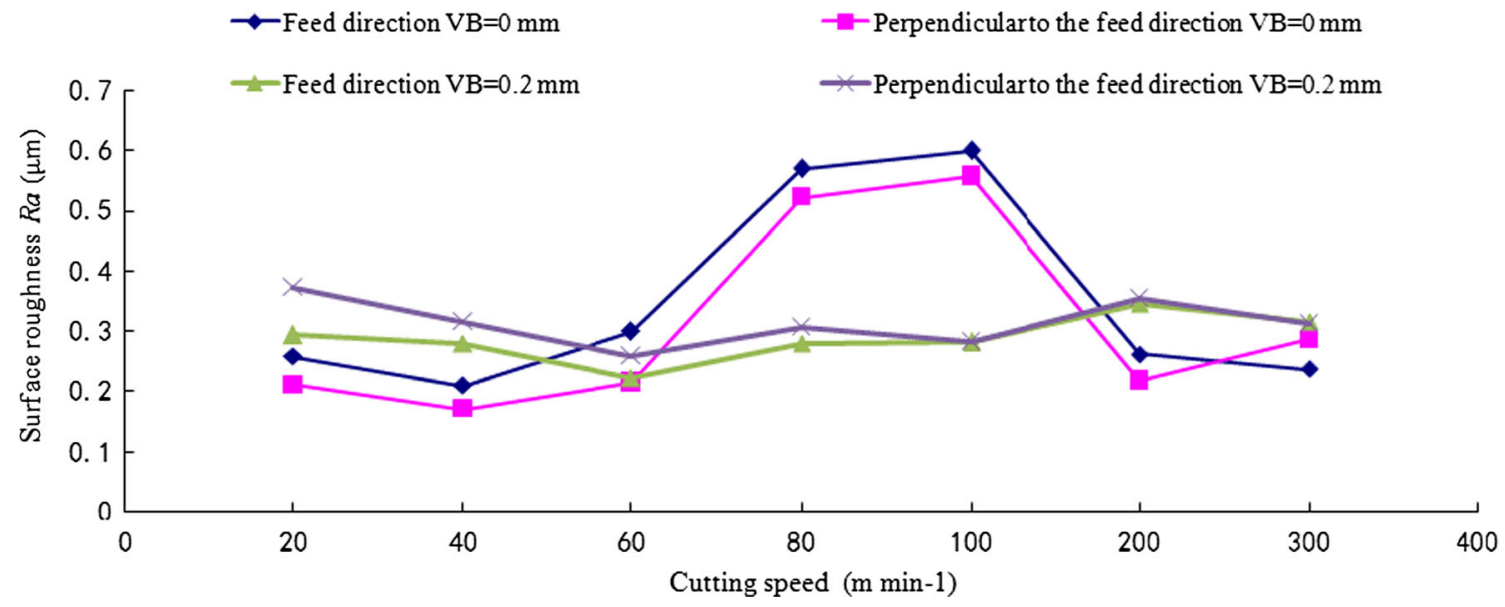

Fig. 3 Influence of cutting speed on surface roughness 


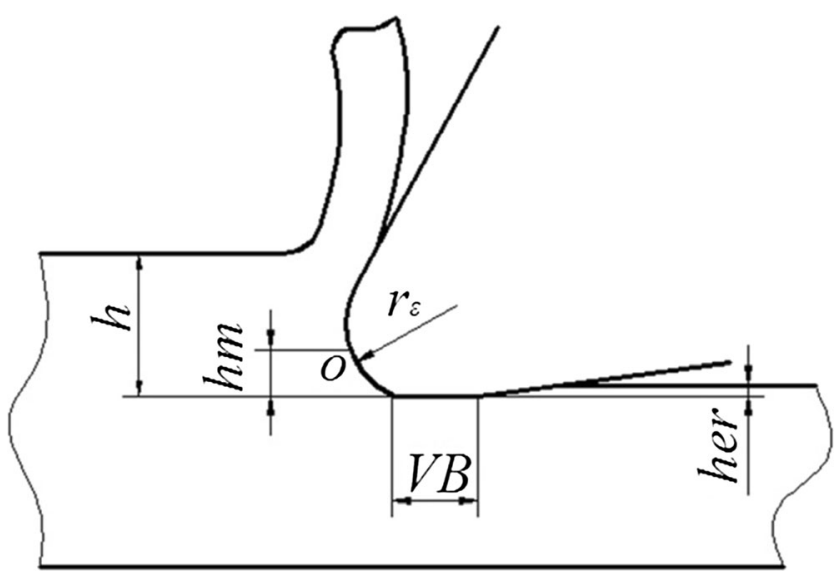

Fig. 5 Diagram of the machined surface forming process

workpiece material to the tool nose. Hence, roughness values slightly change with increasing cutting speed.

Surface roughness perpendicular to the feed direction is greater than that in the feed direction (Fig. 4). When VB increases from 0 to $0.2 \mathrm{~mm}$, roughness decreases. However, when VB reaches $0.35 \mathrm{~mm}$, roughness increases significantly. This result can be attributed to high tool wear at the cutting edge close to the nose and the fracture at the nose. In addition, tool edge radius $r_{\varepsilon}$ is altered with tool flank face wear (Fig. 5). Under point $\mathrm{O}$ in metal slip line $\mathrm{OM}$, plastic deformation layer $h_{\mathrm{m}}$ significantly increases. Thus, tool flank friction extrusion is enhanced, cutting force is increased, the generated elastic deformation and plastic deformation are increased, lateral flow and uplift effect rise, and roughness values in both directions are increased. Weon Kim K. et al. [31] reported that when tool edge radius decreases, cutting temperatures and the generated forces decrease. Tool wear is best maintained at $\mathrm{VB}<0.2 \mathrm{~mm}$ in finish machining of titanium to decrease surface roughness.

Surface topography (Fig. 6) explicitly shows the track movement of the cutting edge. The shape of the cutting edge is copied on the machined surface. 3D surface topography images contain more information than those obtained from a surface profilometer. We noted that $3 \mathrm{D}$ image covers $(857 \mu \mathrm{m} \times 638 \mu \mathrm{m})$ of the machined surface samples rather than straight-line measurements are obtained by using a surface profilometer (in Fig. 6, the left side shows 3D surface topography images, whereas the right side shows $2 \mathrm{D}$ wave images). The average value of surface roughness Ra can be calculated by using peak height $R_{\mathrm{p}}$ and valley depth $R_{\mathrm{v}}$ of the machined surface waves. We noted that $R_{\max }$ (the maximum height of roughness) describes the sum of the maximum $R_{\mathrm{p}}$ and the maximum $R_{\mathrm{v}}$ of the contour curve at the reference length. When the amplitude observed by 3D surface topography is small, the produced surface roughness is uniform, and thus, good. The examination of machined surface samples by a new tool cutter presents better topography amplitude than the examination made by a worn tool cutter. This finding can be attributed to tool wear at the cutting edge close to the nose that results in large groove marks.

\subsubsection{Defects}

Three types of defects can be observed by examining the machined surface, as follows.

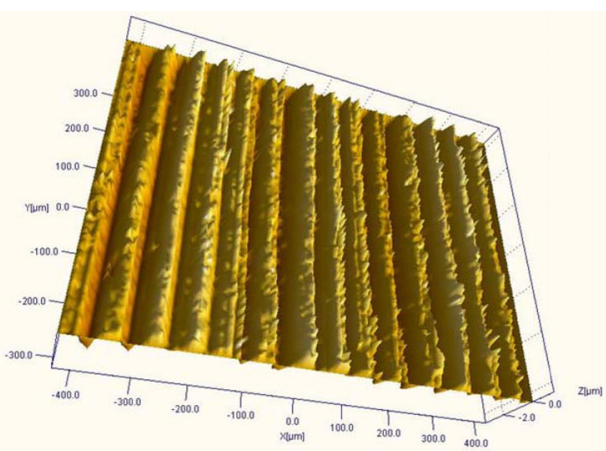

(a)

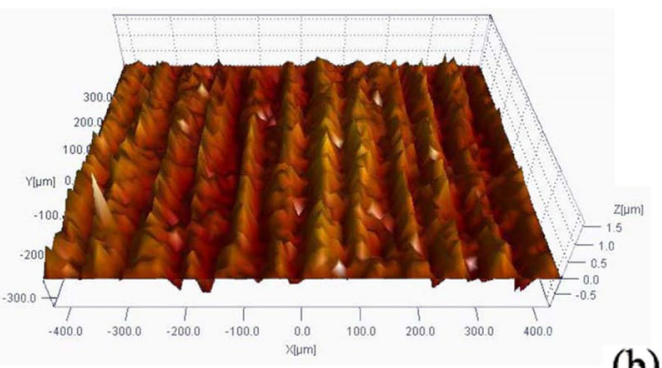

(b)
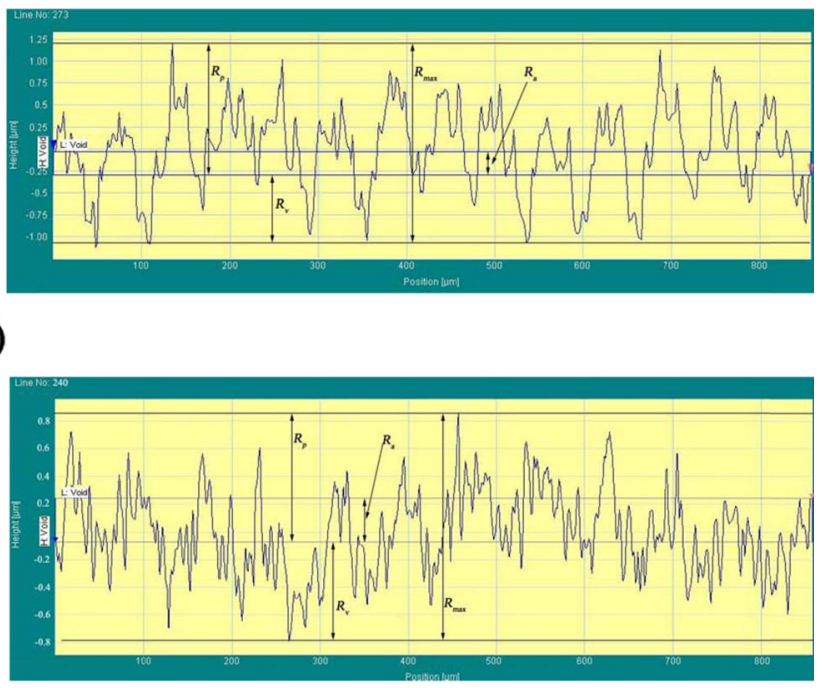

Fig. 6 Surface topography. a $V B=0 \mathrm{~mm}, V \mathrm{c}=40 \mathrm{~m} \mathrm{~min}^{-1}$. b VB=0.2 $\mathrm{mm}, V \mathrm{c}=40 \mathrm{~m} \mathrm{~min}^{-1}$ 
Feed mark This defect is observed on all machined surface samples. Feed mark is a natural defect that results from feeding. Figure 7 shows an image of a typical feed mark. A high cutting speed and an intensive flank wear produce a significant feed mark on the machined surface. The machined surface is characterized by feed marks without scratches or pits at a cutting speed of less than $40 \mathrm{~m} \mathrm{~min}^{-1}$ by using a new tool. We noted that feed marks are produced by tool rotation caused by cutting speed $(V \mathrm{c})$ and tool toward movement owing to feed speed $\left(V_{\mathrm{f}}\right)$ together map the lay pattern [12]. In addition, many microchip debris are frequently and clearly observed. This defect is caused by random fractured chips deposited on the machined surface.

Tearing surface These defects are randomly observed on machined surface samples, as follows.

Smeared material With prolonged machining, smearing of the workpiece material occurs, and feed marks become less sharp, as shown in Fig. 8a. Smearing can be caused by the side flow of a workpiece material under the squeezing action between the minor flank face and the machined surface when the tool moves along the feed direction.

Microvoids Surface microvoids are randomly located on the workpiece surface. Surface microvoids, as shown in Fig. 8a, b, are associated with the carbide particles in the workpiece material, the particles peeling off the cutting tool, and builtup edge (BUE). Given that the carbide particles in the material, a small part of the cutting tool, and a part of BUE are harder than the workpiece material, the hard particles cannot be deformed at the plasticized layer. Hence, the hard particles crack to relieve strain. Then, these particles are removed from the machined surface, thus leaving the chip and microvoids on the machined surface. Surface microvoids, which can affect

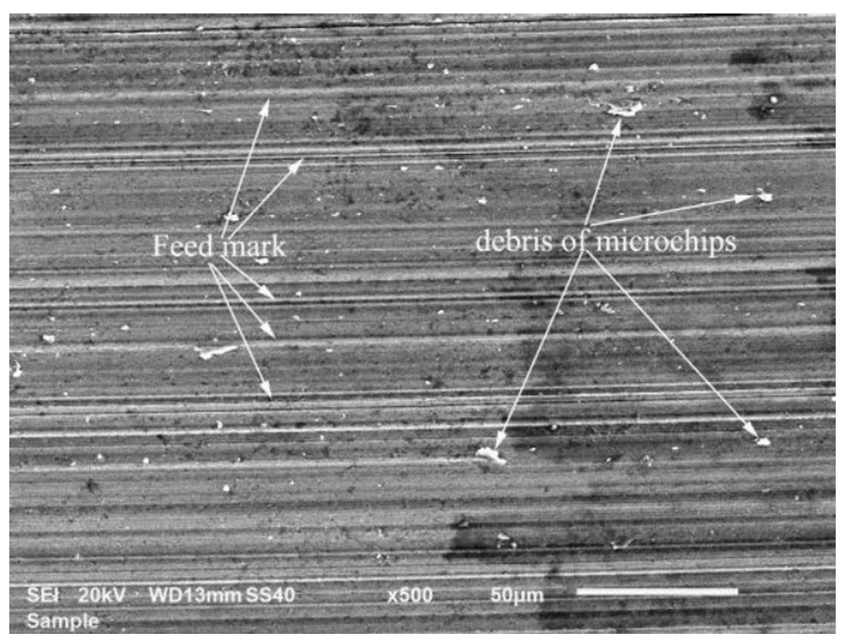

Fig. 7 Lay pattern produced by a new tool $\left(V \mathrm{c}=40 \mathrm{~m} \mathrm{~min}^{-1}, \mathrm{fz}=\right.$ $0.08 \mathrm{~mm}^{\text {tooth }}{ }^{-1}, \mathrm{ap}=1 \mathrm{~mm}, \mathrm{ae}=20 \mathrm{~mm}$ ) the subsequent mechanical properties of a workpiece, are undesirable for critical structural components [32].

Scratches and groove Scratches and grooves on the substrate can be observed clearly in Fig. 8a, b. When a tool is worn, the increase in the contact area of the tool-workpiece interface can aggravate the rubbing action of the tool against the workpiece, thus contributing to severe plastic deformation on the workpiece surface region. Large pieces of material from BUE

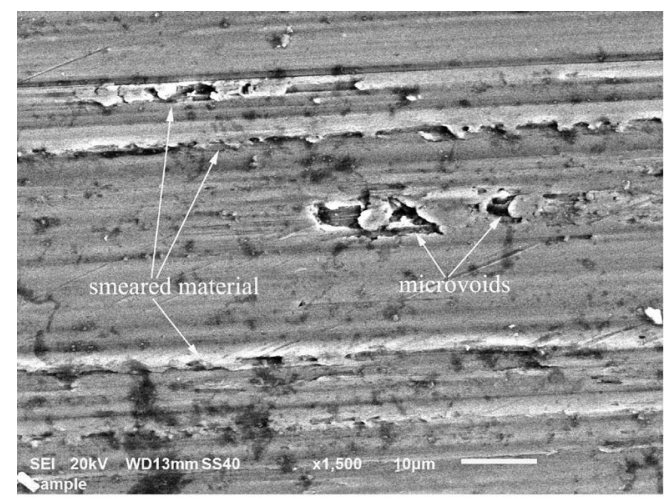

(a)

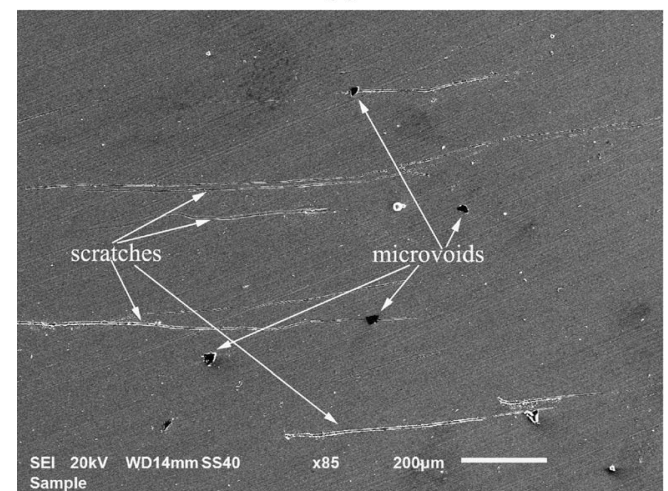

(b)

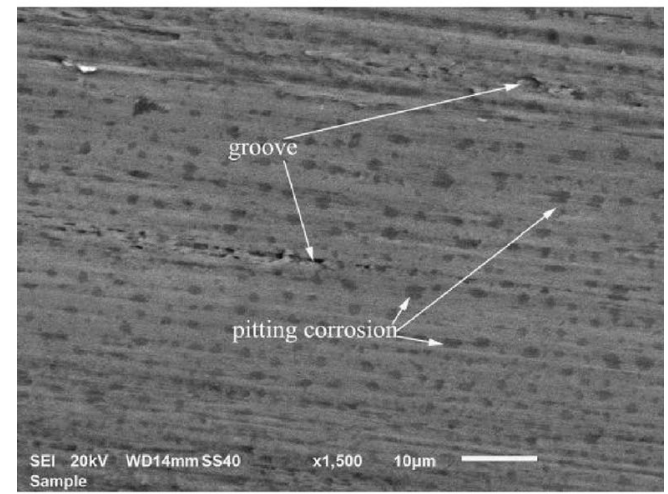

(c)

Fig. 8 Tearing surface (smearing material and surface microvoids. a $V \mathrm{c}=$ $300 \mathrm{~m} \mathrm{~min}^{-1}, \mathrm{fz}=0.08 \mathrm{~mm}$ tooth $^{-1}, \mathrm{ap}=1.0 \mathrm{~mm}, \mathrm{ae}=20 \mathrm{~mm}$ at the initial cutting; microvoids and scratches. b $V \mathrm{c}=300 \mathrm{~m} \mathrm{~min}^{-1}, \mathrm{fz}=0.08 \mathrm{~mm}$ tooth $^{-1}, a p=1.0 \mathrm{~mm}, \mathrm{ae}=20 \mathrm{~mm}$, worn tool $\mathrm{VB}=0.2 \mathrm{~mm}$; groove and pitting corrosion. $\mathbf{c} V \mathrm{c}=300 \mathrm{~m} \mathrm{~min}^{-1}, \mathrm{fz}=0.08 \mathrm{~mm}_{\text {tooth }}^{-1}, \mathrm{ap}=1.0 \mathrm{~mm}$, $\mathrm{ae}=20 \mathrm{~mm}$, worn tool $\mathrm{VB}=0.2 \mathrm{~mm}$ ) 

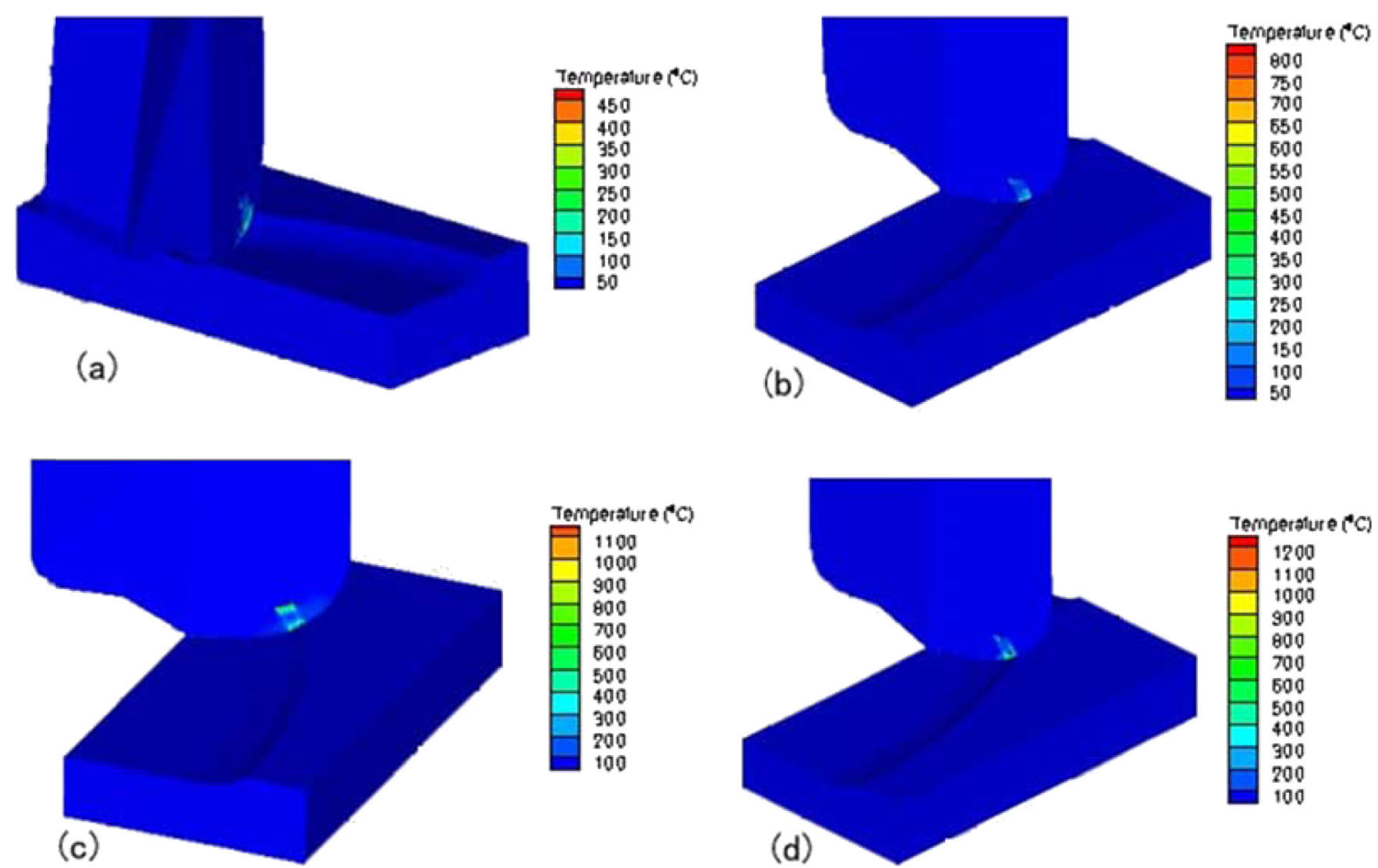

Fig. 9 Temperature distributions on the tool-chip interface. $\mathbf{a} V \mathrm{c}=40 \mathrm{~m} \mathrm{~min}^{-1}, \mathbf{b} V \mathrm{c}=100 \mathrm{~m} \mathrm{~min}^{-1}, \mathbf{c} V \mathrm{c}=200 \mathrm{~m} \mathrm{~min}^{-1}, \mathbf{d} V \mathrm{c}=300 \mathrm{~m} \mathrm{~min}^{-1}$

fragments adhere to the machined surface instead of being diverted from the machining process.

Pitting corrosion Figure 8c shows the occurrence of pitting corrosion on the tearing surface, which can be attributed to the high local cutting temperature generated by high cutting speed $\left(\mathrm{Vc}=300 \mathrm{~m} \mathrm{~min}^{-1}\right.$, cutting temperature exceeds $1,000{ }^{\circ} \mathrm{C}$; Fig. 9). The tool-workpiece interface becomes the melt layer, phase transformation occurs on the surface layer, and a significant number of oxides and metal debris adhere to the machined surface.

Temperature distribution on the tool-chip interface is analyzed by using the commercial finite element analysis software Third Wave AdvantEdge ${ }^{\mathrm{TM}}$. The cutting temperature finite element analysis parameters are listed in Table 4 and shown in Fig. 9. Temperature is measured at different locations at cutting speeds of 40,100, 200, and $300 \mathrm{~m} \mathrm{~min}^{-1}$. Cutting temperature exceeds $800{ }^{\circ} \mathrm{C}$ when cutting speed is over $100 \mathrm{~m} \mathrm{~min}^{-1}$. Metal melting and phase transformation occur at high temperatures (T-1023 solution aging temperature is $\left.760{ }^{\circ} \mathrm{C}[25]\right)$.

Burr formation Machining burr defects are frequently observed in the area where the tool exits the cutting zone. Burr formation easily causes stress concentration and decreases the fatigue life of components. Therefore, burr formation must be reduced or prevented. Machining burrs are generally classified according to the type of cutting edge and the mechanism of their formation [33, 34]. In free orthogonal milling experiments, only the main cutting edge is engaged, thus producing a sideward burr, which is referred to as a Poisson burr or a top burr [33-35]. The sideward burr is a result of the tendency of a material to bulge at the sides when compressed until permanent plastic deformation occurs [34]. This tendency is caused by high biaxial compressive stress that pushes the material toward the free surface [36, 37]. Therefore, burr

Table 4 Cutting temperature finite element analysis parameters

\begin{tabular}{ll}
\hline Workpiece length & $3.0 \mathrm{~mm}$ \\
Workpiece width & $5.0 \mathrm{~mm}$ \\
Workpiece height & $2.0 \mathrm{~mm}$ \\
Workpiece material & Ti- 1023 \\
Radial rake angle & $12^{\circ}$ \\
Axial rake angle & $7^{\circ}$ \\
Edge radius & $0.02 \mathrm{~mm}$ \\
Tool material & Carbide-general \\
Tool coating parameters (2 layers) & TiAlN, 0.02 mm TiN, $0.015 \mathrm{~mm}$ \\
Tool model & SolidWorks Model \\
& $0.5 \mathrm{~mm}$ \\
Axial depth of cut & $5^{\circ}$ \\
Angle of rotation & $0.08 \mathrm{~mm}$ \\
Feed per tooth & $40,100,200,300 \mathrm{~m} \mathrm{~min}{ }^{-1}$ \\
Spindle speed & Down milling \\
Milling process type & Immersed \\
Coolant area option & $\sigma\left(\varepsilon^{p}, \bar{\varepsilon} T\right)=g\left(\varepsilon^{p}\right) * \Gamma(\bar{\ddagger} * \Theta(T)$ \\
Constitutive model &
\end{tabular}


formation is closely related to the stress state and thus, to the integrity of the generated surface. The size of a burr is a function of material properties, the effective dimensions of the notch detected at the major cutting edge, and the pressure at the effective radius and flank of the tool. The pressure and, thus, the tendency to form burrs are particularly high on materials with low thermal conductivity and low Young's modulus [34].

Figure 10 shows the surfaces and machining burrs of the workpiece in the area where the tool exits the cutting zone during titanium milling at different cutting speeds and VB values. Similar to the surfaces generated in free orthogonal milling, burr formation increases when VB increases. Burr formation is generally more pronounced at low cutting speeds than at high cutting speeds. When VB increases, the effect of notch wear also increases. In the notch wear area, a welldefined material separation is hindered. Hence, chip formation and chip flow are affected. Furthermore, a part of the material in the peripheral zone of the workpiece is not removed as chips but remains on the workpiece as burrs. Consequently, an increase in burr formation is also observed with an increase in VB, as shown in Fig. 10a, b, c, d. Simultaneously, burr increases notch wear of the tool. Machai and Biermann [38] showed that notch wear at the major cutting edge may be caused by fatigue damage resulting from the fin-shaped chip and the sawtooth-shaped burrs. When cutting temperature at the tool-workpiece interface significantly increases with cutting speed greater than $300 \mathrm{~m} \mathrm{~min}^{-1}$ (Fig. 9), cutting force is reduced, the generated plastic deformation decreases, and burr formation during prolonged cutting reduces mechanical effect at the major cutting edge. We also observed that the size of the burr decreases with the significant increase in cutting speed, as shown in Fig. 10a, b, c, d.

\subsection{Microhardness}

The results for machined surface microhardness are shown in Fig. 11. This figure shows that microhardness increases initially and then decreases with the increase in cutting speed when a new tool is used. At cutting speeds less than $60 \mathrm{~m} \mathrm{~min}^{-1}$, the plastic deformation of the cutting area increases, the strengthening effect of plastic deformation is enhanced, and machined surface hardness increases with the rise in cutting speed. At cutting speeds greater than $60 \mathrm{~m} \mathrm{~min}^{-1}$, the contact time of the tool flank with the materials is short, plastic deformation of the cutting area decreases, cutting temperature increases, and the machined surface is fully softened with the rise in cutting speed. Hence, machined surface hardness decreases. Wear on the cutting edge affects the microstructure. Surface hardening occurs when machining is conducted by using a worn tool at different cutting speeds (Fig. 11). The microhardness of the machined surface decreases with increasing cutting speed. This result can be attributed to the deformation on the flank face and high machining pressure at low cutting speed. However, softening of the machined surface material is probably caused by high cutting temperature on the tool-workpiece interface at high cutting speeds.
Fig. 10 Burr formation

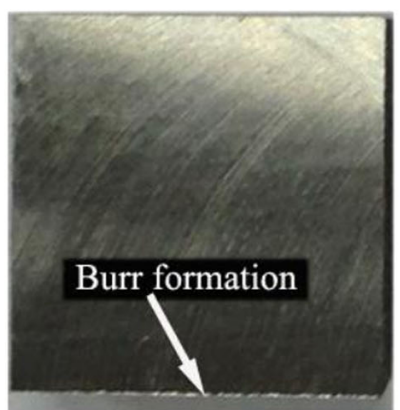

(a)New tool $V c=40 \mathrm{~m} \mathrm{~min}^{-1}$

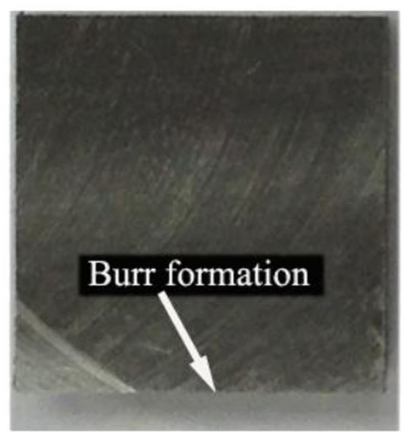

(c)New tool $V c=300 \mathrm{~m} \mathrm{~min}^{-1}$

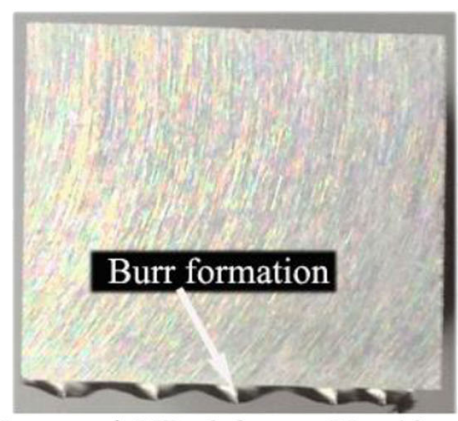

(b) Worn tool $V B=0.2 \mathrm{~mm} \mathrm{Vc}=40 \mathrm{~m} \mathrm{~min}^{-1}$

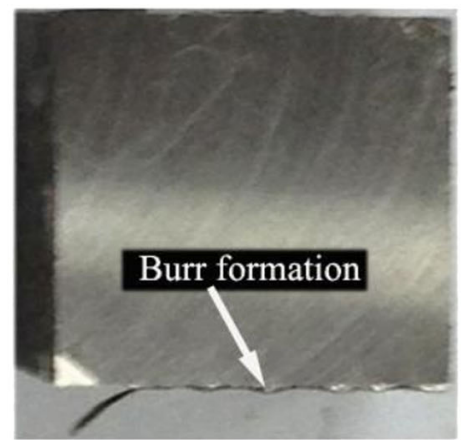

(d)Worn tool $V B=0.2 \mathrm{~mm} V c=300 \mathrm{~m} \mathrm{~min}^{-1}$ 
Fig. 11 Surface microhardness

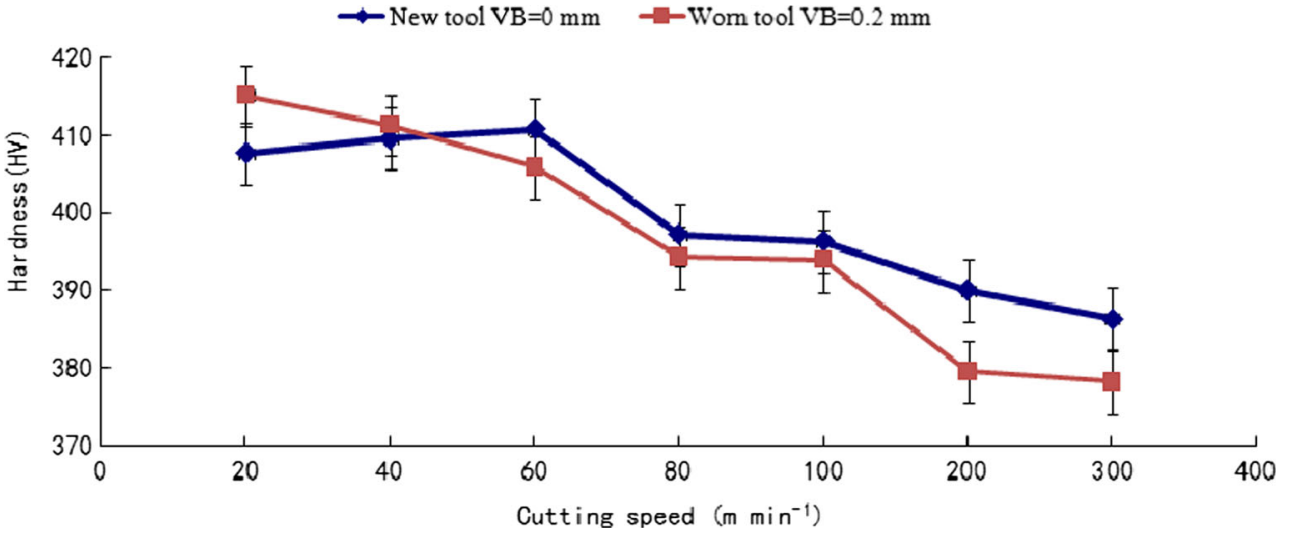

The depth of hardening below the machined surface in this study is shown in Figs. 12 and 13. As shown in Fig. 12, microhardness exhibits the same trend at different cutting speeds with a new tool or a worn tool. However, the depth of hardening by a worn tool is greater than that by a new tool. Microhardness on the machined surface starts with a value higher than that of the bulk material when a new tool is used. The starting value is approximately $9 \%$ higher than bulk material hardness. Microhardness decreases to the hardness of the bulk material $(\sim 375 \mathrm{HV})$ at a depth of approximately 20 to $35 \mu \mathrm{m}$ below the machined surface. The softening region cannot be observed in Fig. 12. However, for $\mathrm{VB}=0.2 \mathrm{~mm}$, the starting value on the machined surface is less than $6 \%$, which is higher than bulk material hardness. Microhardness decreases to $378 \mathrm{HV}$ at a depth of approximately 15 to $20 \mu \mathrm{m}$ below the machined surface, reaches its peak at 30 to $40 \mu \mathrm{m}$, and then decreases gradually to the hardness of the bulk material at cutting speeds less than $100 \mathrm{~m} \mathrm{~min}^{-1}$. However, this starting value on the machined surface is approximately similar to bulk material hardness. Then, hardness increases to $393 \mathrm{HV}$ at a depth of approximately 6 to $8 \mu \mathrm{m}$ below the machined surface and decreases gradually to the hardness of the bulk material at cutting speeds greater than $100 \mathrm{~m} \mathrm{~min}^{-1}$. Hence, the softening region can be observed in Fig. 12. The generated hardness mainly results from corner radius extrusion, severe friction between the tool flank and the machined surface, high pressure during chip formation, cutting heat in the cutting area, and poor thermal conductivity of Ti-1023. Work hardening occurs when high machining pressure and temperature are generated during machining [8]. In addition, milling is an interrupted cutting process. When the milling tool (entry) starts milling the workpiece, heat accumulation occurs. Correspondingly, when the milling tool (exit) stops milling the workpiece, cooling occurs. Hence, internal work hardening is an accumulation of the cyclic process. In Fig. 13, when cutting speed is within the range of 20 to $100 \mathrm{~m} \mathrm{~min}^{-1}$ by using a new tool, the depth of hardening is approximately 25 to $35 \mu \mathrm{m}$. However, the depth of hardening decreases with
Fig. 12 Microhardness below the subsurface

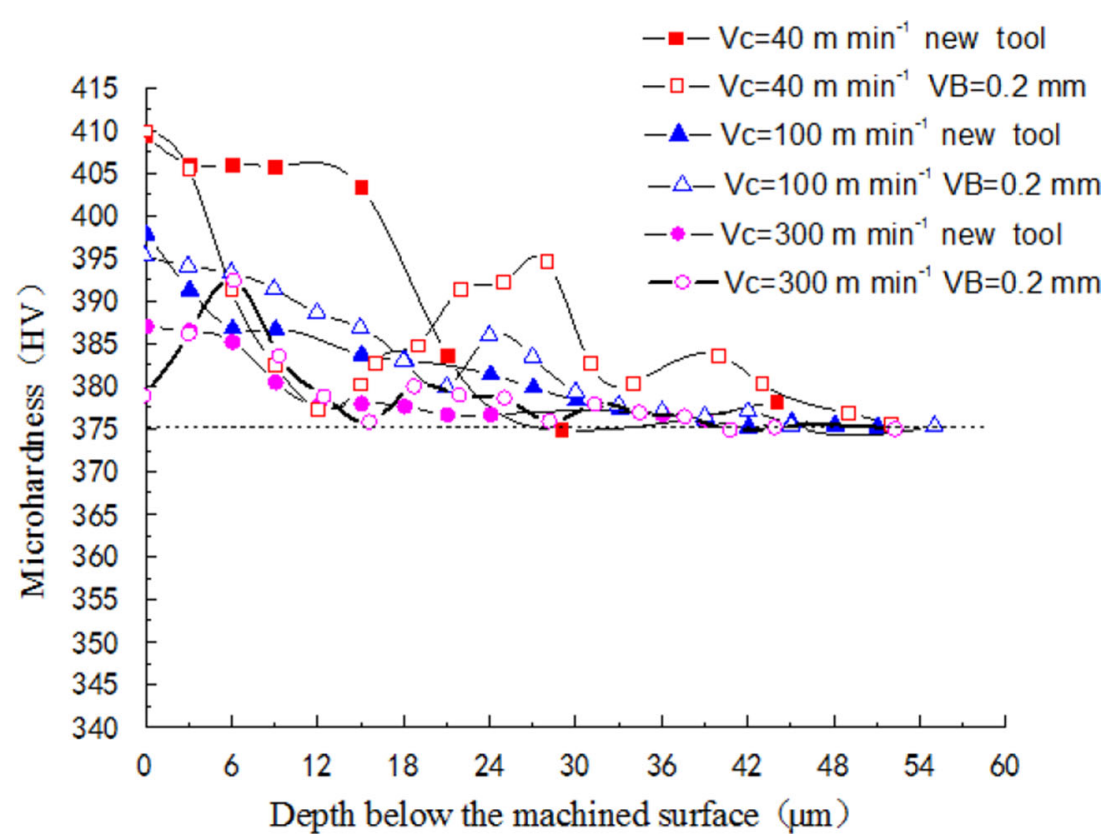


Fig. 13 Depth of hardening at the subsurface

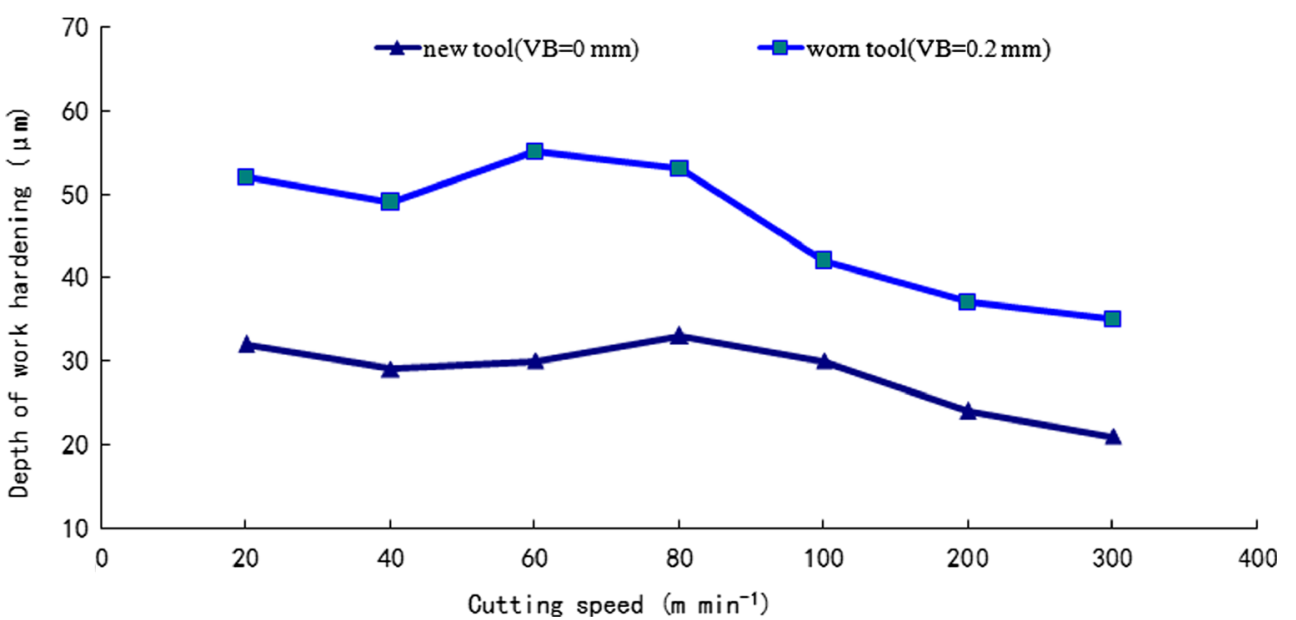

the increase in cutting speed when cutting speed exceeds $100 \mathrm{~m} \mathrm{~min}^{-1}$. When machining is conducted by using a worn tool at $\mathrm{VB}=0.2 \mathrm{~mm}$, the depth of hardening is approximately 35 to $55 \mu \mathrm{m}$. Therefore, the depth of hardening decreases with the increase in cutting speed.

The subsurface of the machined samples can be divided into two regions, as shown in Fig. 14, i.e., hard and bulk material regions. Plastic deformation and grain size are directly related to hardness values. We conclude that microhardness modification on the machined subsurface may result in high temperature because Ti-1023 has low thermal conductivity [39].

Figures 15 and 16 show the depth of hardening below the machined surface at different VB values. As shown in Fig. 15, microhardness exhibits the same trend at different $\mathrm{VB}$ values. When $\mathrm{VB}=0$, as shown in Fig. 15a, microhardness (400 HV) decreases to the hardness of the bulk material. When $\mathrm{VB}=$ $0.1 \mathrm{~mm}$, as shown in Fig. 15b, microhardness decreases from 400 to $383 \mathrm{HV}$ at a depth of $10 \mu \mathrm{m}$ below the machined surface, reaches a peak at $30 \mu \mathrm{m}$, and then decreases again to matrix hardness. When $\mathrm{VB}=0.2 \mathrm{~mm}$, as shown in Fig. $15 \mathrm{c}$, microhardness decreases from 400 to $378 \mathrm{HV}$, exhibits a valley at a depth of $20 \mu \mathrm{m}$ below the machined surface and a peak at $40 \mu \mathrm{m}$, and then gradually decreases again to matrix hardness. When $\mathrm{VB}=0.35 \mathrm{~mm}$, as shown in Fig. $15 \mathrm{~d}$, microhardness decreases from 390 to $375 \mathrm{HV}$, exhibits a valley at a depth of $20 \mu \mathrm{m}$ below the machined surface and a peak at $407 \mathrm{HV}$ and $68 \mu \mathrm{m}$, and then gradually decreases again to matrix hardness. Microhardness on the subsurface follows the "surface enhancing-thermal softening-restrengthening-stabilizing" process, wherein the hardening and softening regions appear. Surface hardening is consistent with the finding of Chen [40] during high-speed milling of Ti-6A1-4V. In Fig. 16, when VB ranges from 0 to $3.5 \mathrm{~mm}$, the depth of hardening increases by approximately 30 from $130 \mu \mathrm{m}$. Tool wear influence on the hardened layer is evident, and the depth of hardening increases with increasing VB. Subsurface hardening and the softening zone appear when $\mathrm{VB} \geq 0.1 \mathrm{~mm}$.

When the workpiece material is subjected to high cutting temperature, high cutting pressure is generated during machining. Cutting forces increase during the intermittent cutting process when the cutting edge becomes blunt with the increase in VB. Hence, the material in the cutting zone generates a high level of normal compressive stress. Slipped, elongated, and broken grains are intense under the subsurface. Therefore, the depth of hardening increases. In addition, cutting temperature increases when the friction between the tool-chip interface and the toolworkpiece interface increases. This finding is attributed to plastic deformation of the workpiece material in the cutting zone. Therefore, the depth of hardening also increases. Given that Ti-1023 is ductile and has low thermal conductivity, cutting temperature is maintained for a certain period under the subsurface, and a shallow layer of considerably deformed material can be formed at high temperatures during cutting. The depth of hardening

Fig. 14 Hard region beneath the machined surface

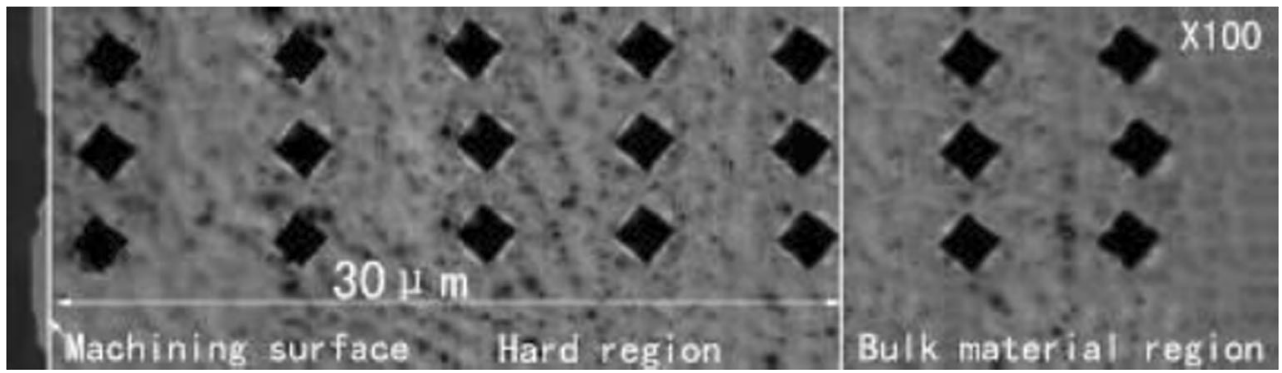



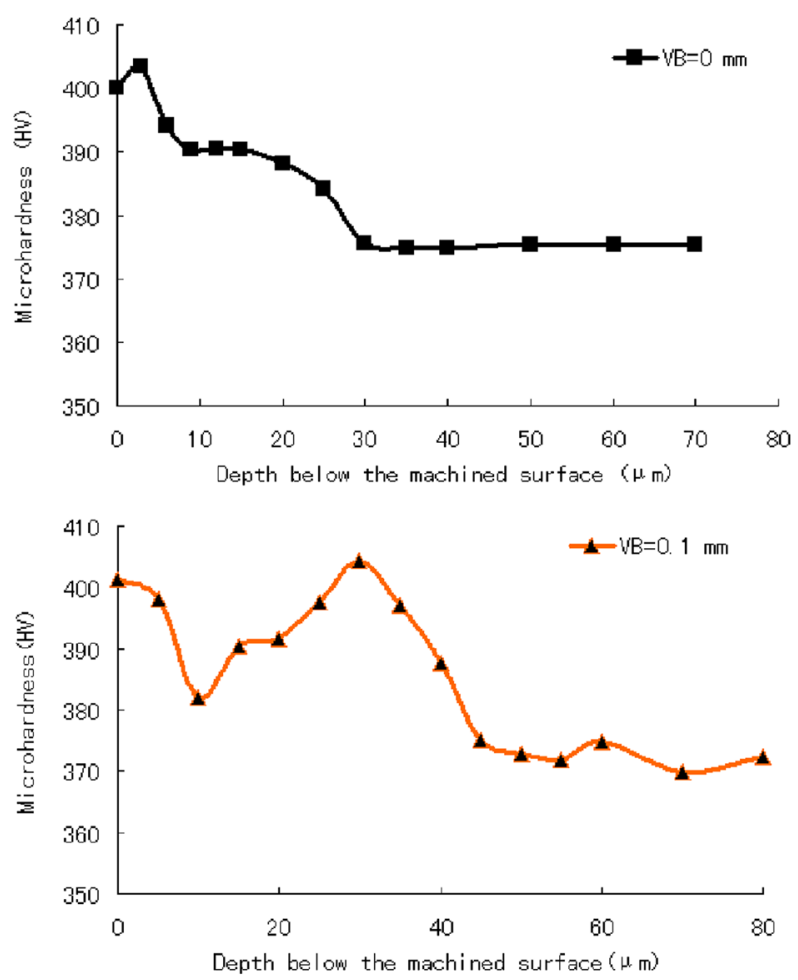

(a)

(b)
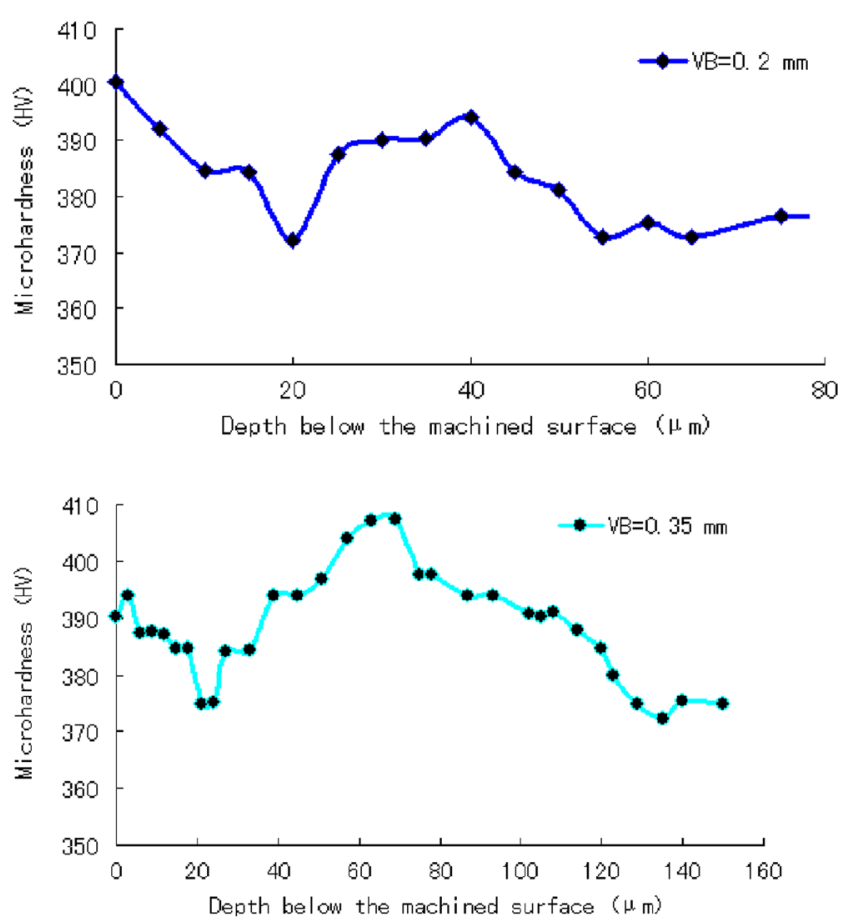

(c)

(d)

Fig. 15 Influence of VB on the depth of hardening $\left(V \mathrm{c}=60 \mathrm{~m} \mathrm{~min}^{-1}, \mathrm{fz}=\right.$ $0.08 \mathrm{~mm}, \mathrm{ap}=1 \mathrm{~mm}$ )

increases gradually when VB increases from 0 to $0.2 \mathrm{~mm}$. The hardened layer increases significantly as VB exceeds $0.3 \mathrm{~mm}$. The depth curve of work hardening exhibits evident valleys because cutting forces and cutting

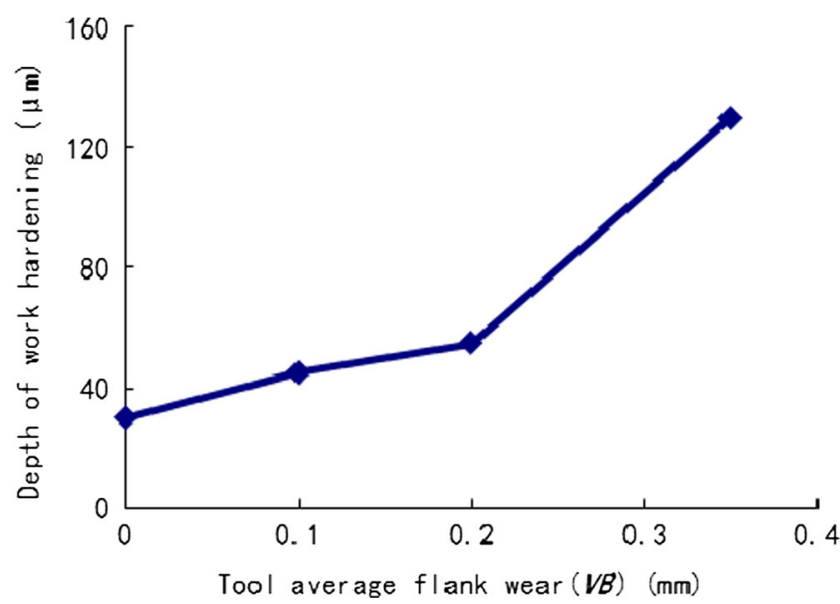

Fig. 16 Influence of $\mathrm{VB}$ on microhardness $V \mathrm{c}=40 \mathrm{~m} \mathrm{~min}^{-1}(V \mathrm{c}=$ $60 \mathrm{~m} \mathrm{~min}^{-1}, \mathrm{fz}=0.08 \mathrm{~mm}$ tooth $\left.{ }^{-1}, \mathrm{ap}=1 \mathrm{~mm}\right)$

temperature increase significantly. This finding can be attributed to the plastic deformation or microstructural alteration of the subsurface, as shown in Fig. 19. Tool wear is best controlled at $\mathrm{VB}<0.2 \mathrm{~mm}$ in finish machining of titanium to decrease the depth of the hardening layer.

Some researchers have reported that hardness measured at the top subsurface is slightly lower than that of the bulk material. This phenomenon is attributed to surface softening $[7,8,12]$. In the current study, surface softening is not observed when machining Ti-1023. However, the softening zone is observed when $\mathrm{VB} \geq 0.1 \mathrm{~mm}$. This finding is attributed to work hardening caused by the plastic deformation or microstructural alteration of the subsurface.

\subsection{Microstructure}

Cross sections of the machined surface samples produced by new and worn tools at different cutting speeds are shown in Figs. 17, 18, and 19. Subsurface microstructural deformation caused by machining consists of deformed grain boundaries in the direction of cutting (Fig. 18) and elongation of grains (Fig. 19). These types of defects are typically reported during machining of titanium alloys [7, 8]. Observations of Figs. 17, 18 , and 19 enable us to conclude that the microstructure at the top region to several micrometers beneath the machined surface tends to exhibit plastic deformation. Plastic deformation seems to follow the same direction as feed speed. From observations of the recorded images, we noted that the severity of plastic deformation on the subsurface immediately beneath the machined surface is controlled by cutting speed and tool wear.

Figure 17 shows the cross section of the subsurface microstructure from the machined surface at different cutting speeds when using a new tool (initial wear). No significant microstructural alteration or deformed grain 

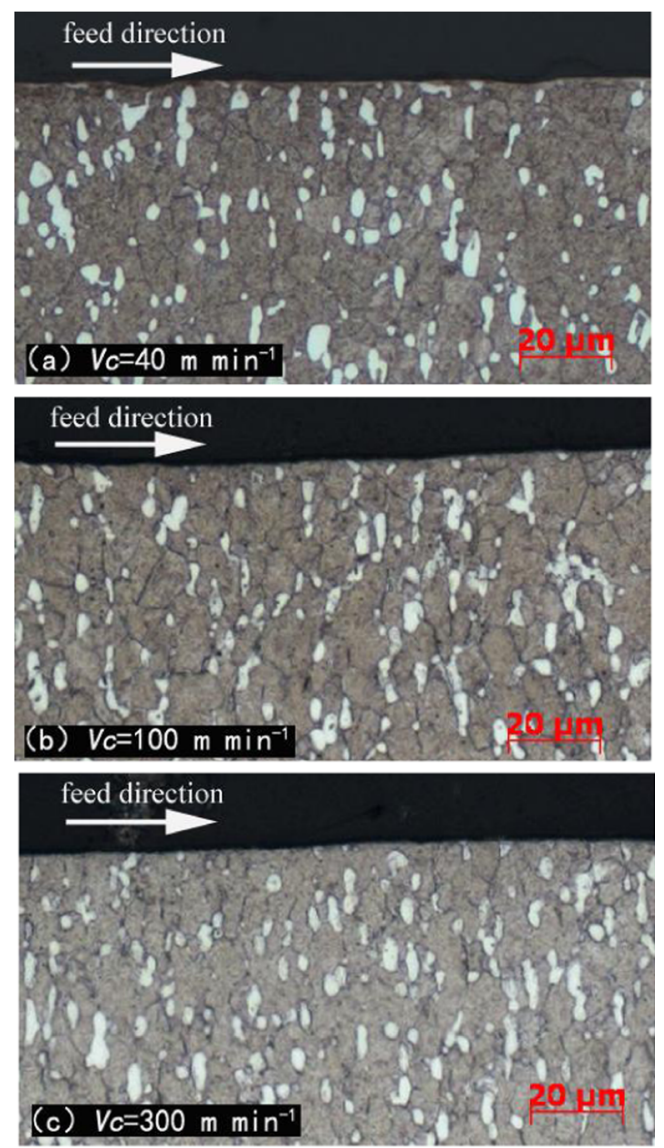

Fig. 17 Influence of cutting speed on subsurface microstructure (initial wear, $\mathrm{fz}=0.08 \mathrm{~mm}$ tooth $^{-1}, \mathrm{ap}=1 \mathrm{~mm}$ )

resulting from low cutting pressure and cutting temperature was observed. The subsurface microstructure near the surface tends to exhibit plastic deformation. This form of microstructural alteration is typically associated with the highly localized surface heating caused by abusive machining or a worn tool [20]. Slight plastic deformation of a layer of the machined surface is observed at different cutting speeds of 40,100 , and $300 \mathrm{~m} \mathrm{~min}^{-1}$, as shown in Fig. 18. By contrast, a considerably deformed area can be observed for samples generated by a worn tool, with $\mathrm{VB}=$ $0.2 \mathrm{~mm}$ at different cutting speeds. With the increase in cutting speed from low to high, plastic deformation and deep alteration of the microstructure decrease. Plastic deformation on the machined surface is caused by high cutting pressure at high temperature during the machining process. Prolonged machining by using a worn tool from the initial wear to $\mathrm{VB}=0.35 \mathrm{~mm}$ produces severe plastic deformation and deep alteration of the microstructure on the machined surface, as shown in Fig. 19. A shallow layer of considerably deformed material can be formed at high temperature and high cutting pressure produced during cutting. Thus, the findings are consistent with the expected behavior described previously.
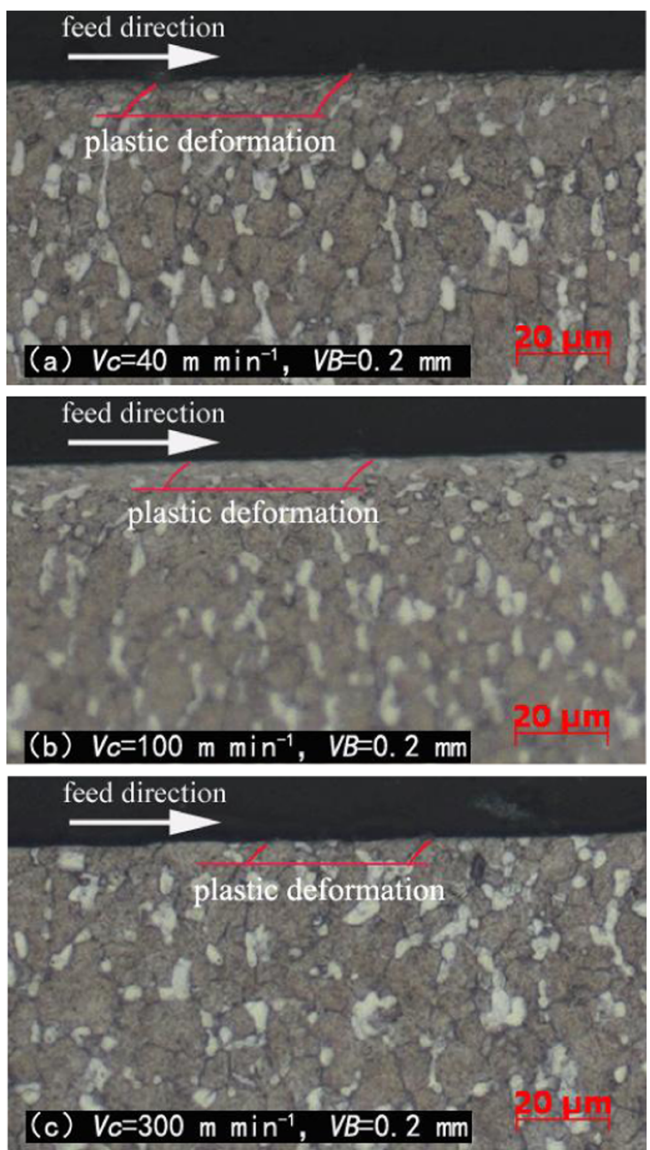

Fig. 18 Influence of cutting speed on subsurface microstructure (tool average flank wear $\mathrm{VB}=0.2 \mathrm{~mm}, \mathrm{fz}=0.08 \mathrm{~mm}$ tooth $^{-1}$, ap=1 mm)

No white interface layer has been observed in all samples, as reported by Che-Haron and Jawaid [7]. The workpiece is machined under cooling conditions, and milling temperature is too low to cause any phase transformation. Hence, white layer cannot be observed under the machined surfaces.

\section{Conclusions}

In this study, surface roughness, defect, microstructure, and microhardness are investigated in machining the titanium alloy Ti-1023 with a cemented carbide tool at various cutting speeds. The main results are summarized as follows.

(1) Cutting speed and VB can significantly affect the surface integrity of Ti-1023 during face milling.

(2) Surface roughness increases when cutting speed decreases within the range of $40-100 \mathrm{~m} \mathrm{~min}^{-1}$. However, surface roughness decreases at high cutting speeds within the range of $100-300 \mathrm{~m} \mathrm{~min}^{-1}$. Surface texture is smooth and regular at the cutting speed of $40 \mathrm{~m} \mathrm{~min}^{-1}$ when a new tool is used. Moreover, surface roughness 

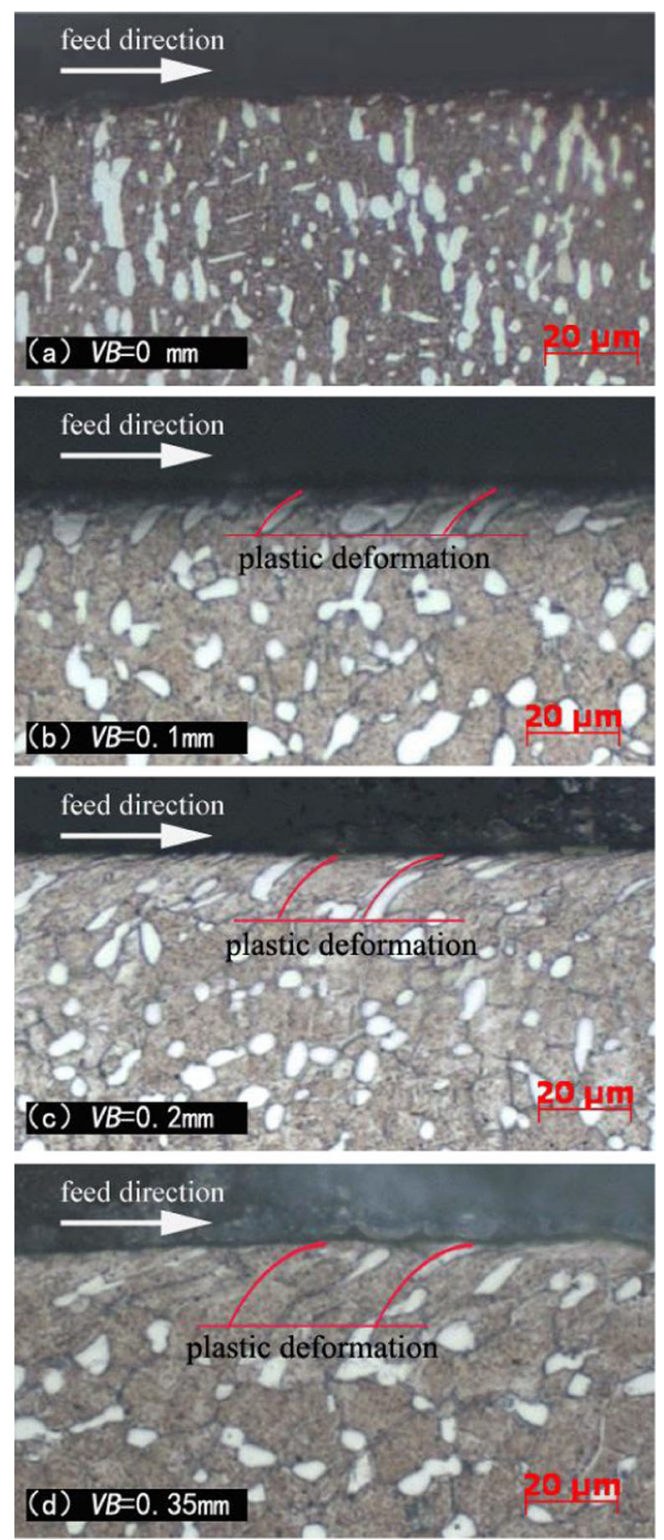

Fig. 19 Influence of $\mathrm{VB}$ on subsurface microstructure $\left(V \mathrm{c}=60 \mathrm{~m} \mathrm{~min}^{-1}\right.$, $\mathrm{fz}=0.08 \mathrm{~mm}$ tooth $^{-1}, \mathrm{ap}=1 \mathrm{~mm}$ )

values are stable with the increase in cutting speed when a worn tool is used at $\mathrm{VB}=0.2 \mathrm{~mm}$ and increases with the increase in VB.

(3) Feed mark is a natural defect caused by feeding. Microvoids are associated with the carbide particles in the workpiece material, the particles peeling off the cutting tool, and BUE. Smearing is caused by the side flow of the workpiece material when the tool moves along the feed direction. When the tool is worn, scratches and grooves on the substrate can be observed clearly. Pitting corrosion on the tearing surface can be attributed to localized high cutting temperature generated at high cutting speed or a large number of oxides and metal debris adhering to the machined surface.
(4) Hardening can occur when machining Ti-1023. The depth of hardening decreases with the increase in cutting speed.

(5) The effect of tool wear on hardening is significant. When VB ranges from 0 to $0.2 \mathrm{~mm}$, the depth of hardening increases from 35 to $55 \mu \mathrm{m}$. Then, at $\mathrm{VB}=0.35 \mathrm{~mm}$, the depth of hardening reaches $130 \mu \mathrm{m}$. After a certain degree of tool wear, softening regions are apparent on the subsurface. When tool wear increases, softening regions are more pronounced.

(6) For the subsurface microstructure obtained from the cross sections of the machined surface, no significant phase transformation or evident deformation can be observed at different cutting speeds when a new tool (initial wear) is used. With the increase in cutting speed from low to high, plastic deformation and deep alteration of the microstructure decrease when a worn tool is used at $\mathrm{VB}=0.2 \mathrm{~mm}$. Severe plastic deformation and deep alteration of the microstructure on the machined surface are produced with $\mathrm{VB}$ from the initial wear to $\mathrm{VB}=$ $0.35 \mathrm{~mm}$. No white layer can be observed under various processing conditions.

Acknowledgments The authors would like to appreciate Dr. Sun Jianfei, Xue Chao, Tan Dunming, M.S. Ma Shuang, and Guo ShiKun for their suggestions and assistance during this work.

Open Access This article is distributed under the terms of the Creative Commons Attribution License which permits any use, distribution, and reproduction in any medium, provided the original author(s) and the source are credited.

\section{References}

1. Boyer RR, Briggs RD (2005) J Mater Perform 14:681

2. Pingping Z, Qingjuan W, Qi G, KuaiShe W (2012) Research and application of high-strength $\beta$ Ti alloy (in Chinese). Mater Heat Treat 41:51-54

3. Leskovar P, Ferlan D, Kovac M (1987) Residual stresses as essential criteria for the evaluation of production processed. Ann CIRP 36: 409-412

4. Jang DY, Liou JH, Watkins TR, Kozaczek KJ, Hubbard CR (1995) Characterisation of surface integrity in machined austenitic stainless steel. J Manuf Sci Eng 3:399-413

5. Zhang XP, Liu CR, Yao ZQ (2007) Experimental study and evaluation methodology on hard surface integrity. Int J Adv Manuf Technol 34:141-148

6. Ko TJ, Kim HS (2001) Surface integrity and machine ability in intermittent hard turning. Int J Adv Manuf Technol 18:168-175

7. Che-Haron CH, Jawaid A (2005) The effect of machining on surface integrity of titanium. J Mater Process Technol 166:188-192

8. Sun J, Guo YB (2009) A comprehensive experimental study on surface integrity by end milling Ti-6Al-4V. J Mater Process Technol 209:4036-4042

9. Xiaoyong Y, Chengzu R, Yan W, Guang C (2012) Experimental study on surface integrity of Ti-6Al-4V in high speed side milling. Trans Tianjin Univ 18:206-212 
10. Daymi A, Boujelbene M (2011) Surface integrity in high speed end milling of titanium alloy Ti-6Al-4V. Mater Sci Technol 27:391-392

11. Velasquez JDP, Tidu A, Bolle B (2010) Sub-surface and surface analysis of high speed machined Ti-6Al-4V alloy. Mater Eng 527(10/11):2572-2578

12. Ginting A, Nouari M (2009) Surface integrity of dry machined titanium alloys. Int J Mach Tool Manuf 49:325-332

13. Che-Haron CH (2001) Tool life and surface integrity in turning titanium alloy. J Mater Process Technol 118:231-237

14. Nurul-Amin AKM, Ismail AF, Nor Khairusshima MK (2007) Effectiveness of uncoated WC-Co and PCD inserts in end milling of titanium alloy Ti-6Al-4V, J Mater Process Technol 192-193

15. Mantle AL, Aspinwall DK (2001) Surface integrity of a high speed milled gamma titanium aluminide. J Mater Process Technol 118:143150

16. Arunachalam RM, Mannan MA, Spowage AC (2004) Residual stress and surface roughness when facing age hardened Inconel 718 with CBN and ceramic cutting tool. Int J Mach Tool Manuf 44:879-887

17. Sharman ARC, Hughes JJ, Ridgway K (2004) Workpiece surface integrity and tool life issues when turning Inconel 718 nickel based super alloy. Mach Sci Technol 8(3):399-414

18. Mantle AL, Aspinwall DK (1997) Surface integrity and fatigue life of turned gamma titanium aluminide. J Mater Process Technol 72:413420

19. Field M, Kahles JF, Koster WP (1974) Surface finish and surface integrity, USAF technical report AFML-TR-74-60 Met cut research. Associates Inc., Cinci- natti

20. Durul Ulutan, Tugrul Ozel (2011) Machining induced surface integrity in titanium and nickel alloys: a review, Int $\mathrm{J}$ Mach Tools Manufac, 250-280

21. Jeelani S, Ramakrishnan K (1983) Subsurface plastic deformation in machining 6Al-2Sn-4Zr-2Mo titanium alloy. Wear 85:121-130

22. Jeelani S, Ramakrishnan K (1985) Surface damage in machining titanium 6Al-2Sn-4Zr-2Mo alloy. J Mater Sci 20:3245-3252

23. Hughes JI, Sharman ARC, Ridgway K (2004) The effect of tool edge preparation on tool life and workpiece surface integrity. Proc Inst Mech Eng Part B J Eng Manuf 218:1113-1123

24. Li R, Riester L, Watkins TR, Blau PJ, Shih AJ (2007) Metallurgical analysis and nanoindentation characterization of Ti-6Al-4V workpiece and chips in high through put drilling. Mater Sci Eng A 472: $115-124$

25. JinWen L, Zeng WeiDong W, Huan D, YuXuan TXD, GaoFeng Y, YiGang Z, Yi Z (2010) Effects of mechanical heat-treatment on microstructure and properties of $\mathrm{Ti}-10 \mathrm{~V}-2 \mathrm{Fe}-3 \mathrm{Al}$ alloy. Chin $\mathrm{J}$ Nonferrous Metals 20(Special 1):603-605 (In chinese)

26. China aeronautical materials handbook Editorial (2002) China aeronautical materials handbook (In chinese), China Standard Press, 253273

27. Bouzid Sa1 W, Ben Salah N, Lebrun JL (2001) Int J Mach Tool Manuf 41:443-450

28. Aspinwall DK, Dewes RC, Ng E-G, Sage C, Soo SL (2007) Int J Mach Tool Manuf 47:1839-1846

29. Bhushan RK, Das SK (2010) Effect of machining parameters on surface roughness and tool wear for $7075 \mathrm{Al}$ alloy SiC composite. Int J Adv Manuf Technol 50:459-469

30. FeiYue CH, GuoQiang S, HongChao K, ZhiShou Z, FengShou Z, Lian Z (2011) Influence of thermo-mechanical processing on microstructure and mechanical property of Ti-1023 alloy (in Chinese). J Aeronaut Mater 31(1):49-51

31. Weon KK, Young Lee W, Chol SH (1999) A finite-element analysis of machining with the tool edge considered. J Mater Process Technol $86: 45-55$

32. Xue C, Chen WY (2012) Surface damages generated in hole making of a cast nickel-based alloy. Mater Sci Forum 697-698:57-60

33. Nakayama K, Arai M (1987) Burr formation in metal cutting. Ann CIRP 36(1):33-36

34. Gillespie LK, Blotter PT (1976) The formation and properties of machining burrs. Trans ASME J England 98:66-74

35. Hashimura M, Hassamontr J, Dornfeld DA (1999) Effect of in-plane exit angle and rake angles on burr height and thickness in face milling operation. Trans ASME J Manuf Sci Eng 121:13-19

36. Dornfeld D, Min S (2010) A review of burr formation in machining. In: Burrs-analysis, control and removal. Springer, Berlin, pp. 3-11

37. Wyen C-F, Jaeger D, Wegener K (2012) Influence of cutting edge radius on surface integrity and burr formation in milling titanium. Int J Adv Manuf Technol. doi:10.1007/s00170-012-4507-3

38. Machai C, Biermann D (2011) Machining of $\beta$-titanium-alloy Ti$10 \mathrm{~V}-2 \mathrm{Fe}-3 \mathrm{Al}$ under cryogenic conditions: cooling with carbon dioxide snow. J Mater Process Technol 211:1175-1183

39. Du J, Zhanqiang L, Wan Y (2011) Influence of cutting speed on surface integrity for powder metallurgy nickel-based superalloy FGH95. Int J Adv Manuf Technol 56:553-559

40. Chen Jianling (2009), Study on the machining mechanism and parameters optimization during high speed milling of titanium alloy, Shan dong University, Jinan, PR.China 